\title{
Application of Plasma Technology in Fischer-Tropsch Catalysis for the Production of Synthetic Fuels
}

\author{
James Aluha, François Gitzhofer and Nicolas Abatzoglou* \\ Department of Chemical and Biotechnological Engineering, Université de Sherbrooke, Canada
}

Submission: April 23, 2018; Published: May 08, 2018

*Corresponding author: Nicolas Abatzoglou, Department of Chemical and Biotechnological Engineering, Université de Sherbrooke, Québec, J1K 2R1, Canada, Tel: +1 (819) 821-7904; Email: nicolas.abatzoglou@usherbrooke.ca

\begin{abstract}
A short review of our results is presented on the use of high temperature plasma technology in producing catalysts for application in FischerTropsch synthesis (FTS). Nanometric carbon-supported catalysts based primarily on Co and Fe with various metal formulations were synthesized using an induction suspension plasma-spray (SPS) system. The active catalytic species of the metals and the C-matrix support composing both graphitic (G) and amorphous (D; disordered) carbon were all simultaneously generated in situ within the plasma. The Co/C catalyst was the most active when tested for FTS with high selectivity towards the longer hydrocarbon chains. At $220^{\circ} \mathrm{C}, 2 \mathrm{MPa}$ pressure; gas hourly specific velocity of over $3,600 \mathrm{~cm}^{3} \cdot \mathrm{h}^{-1} \cdot \mathrm{g}^{-1}$ of catalyst, it indicated $\sim 40 \% \mathrm{CO}$ conversion with the following selectivity expressed as $\%$ in the products: $30 \%$ gasoline $\left(\mathrm{C}_{5}-\mathrm{C}_{12}\right), 45 \%$ diesel $\left(\mathrm{C}_{13}-\mathrm{C}_{20}\right)$, and $21 \%$ waxes $\left(\mathrm{C}_{21+}\right)$, with less than $4 \% \mathrm{CH}_{4}$ and trace amounts of $\mathrm{CO}_{2}$. Other catalysts tested include Fe/C, bimetallic $\mathrm{Co}-\mathrm{Fe} / \mathrm{C}$ formulations and those promoted with $\mathrm{Ni}$, Mo, and $\mathrm{Au}-\mathrm{Ni}$. It has been shown that particle size influences FTS when using plasma-synthesized catalysts: thus, particles in the mean size range of $9-11 \mathrm{~nm}$ were more selective towards the diesel fraction and waxes, while larger particles of mean size of $14-21 \mathrm{~nm}$ produced more gasoline. Since SPS technology is a relatively new approach in catalyst synthesis, being a one-step process potentially offers an overall higher efficiency and new prospects for the commercial production of synthetic fuels through FTS.
\end{abstract}

Keywords: Fischer-Tropsch; Catalysts; Plasma-synthesis; Carbon support

Abbreviations: OAC: Alternating Current; ASF: Anderson-Schulz-Flory Product Distribution; BET: Brunner-Emmett-Teller (Surface Area Analysis); BTL: Biomass-To-Liquid; $\mathrm{C}_{4}-\mathrm{C}_{12}$ : Gasoline Fraction; $\mathrm{C}_{13}-\mathrm{C}_{20}$ : Diesel Fraction; $\mathrm{C}_{21+}$ : High Molecular Hydrocarbons, Such As Waxes STR: Continuously-Stirred Tank Reactor; CTL: Coal-To-Liquid; D: Disordered or Amorphous Carbon; DBD: Dielectric Barrier Discharge Plasma; EDX: Energy Dispersive X-Ray Spectroscopy; FCC: Face-Centered Cubic Structure; FTS: Fischer-Tropsch Synthesis; G: Graphitic Carbon; GC: Gas Chromatography; GHSV: Gas Hourly Space Velocity; GTL: Gas-To-Liquid; HT-FTS: High Temperature Fischer-Tropsch Synthesis; HCP: Hexagonal Closed Packing; LT-FTS: Low Temperature Fischer-Tropsch Synthesis; NTP: Non-Thermal Plasma Reactor; P: Pressure (Pa); RF: Radio Frequency; RQA: Rietveld Quantitative Analysis; SEM: Scanning Electron Microscopy; SPS: Suspension Plasma-Spray Technology; T: Temperature(K); TEM: Transmission Electron Microscopy; TOS: Time-On-Stream; 3 $\varphi$-CSTSR: Three-Phase Continuously-Stirred Tank Slurry Reactor; XANES: X - $r$ a y Absorption Near-Edge Structure; XPS: X-ray Photoelectron Spectroscopy; XRD: X-ray Diffraction

\section{Introduction}

Fischer-Tropsch Synthesis (FTS) was discovered in the 1920's by Franz Fischer and Hans Tropsch, and since then, FTS has been studied extensively [1], with four metals, namely Co, $\mathrm{Fe}, \mathrm{Ni}$ and Ru exhibiting great potential for catalytic application. However, only Co and Fe are commercially exploited today [2] to produce synthetic automobile fuels such as gasoline, diesel and many other valuable hydrocarbon products [3]. Working at the lowest reaction temperature of only $150{ }^{\circ} \mathrm{C}$, Ru catalyst is the most active FTS catalyst, yielding products of high molecular weight, but it is expensive [4], while Ni forms nickel carbonyls at high pressure and generates mainly $\mathrm{CH}_{4}$ at higher temperatures [5].

Though very complex due to the occurrence of a high number of desired and undesired side reactions, FTS can be simply viewed as a process that converts syngas (a mixture of
$\mathrm{H}_{2}$ and $\mathrm{CO}$ in a specified ratio) to form polymeric chains of liquid hydrocarbons with a widespread distribution of products as represented by Equation (1):

$$
n \mathrm{CO}+n \mathrm{H}_{2} \stackrel{\text { yields }}{\longrightarrow}-\left[\mathrm{CH}_{2}\right]_{n}-+n \mathrm{H}_{2} \mathrm{O}(1)
$$

FTS works in two modes. The high-temperature process (HTFTS) operates on Fe-based catalysts between $300-350{ }^{\circ} \mathrm{C}$ and produces mainly gasoline and linear low molecular-mass olefins, while the low- temperature process (LT-FTS) operates between 200- $240{ }^{\circ} \mathrm{C}$ using Co catalysts, which produce high molecularmass hydrocarbons and linear waxes [1]. Product separation into various fractions is accomplished through distillation columns, and since some product overlaps exist in the components, in this discussion the fractions are classified as follows: gasoline $\left(\mathrm{C}_{5}\right.$ $\left.\mathrm{C}_{12}\right)$, diesel $\left(\mathrm{C}_{13}-\mathrm{C}_{20}\right)$ and waxes $\left(\mathrm{C}_{21+}\right)$. 
Numerous concerns have been expressed involving global warming in particular, and due to increased greenhouse gases in the atmosphere [6], it is generally thought that future production of cleaner fuels will benefit from the FTS path. Increasing regulatory measures through stringent legislation, as well as the push for sulphur-free diesel are seen as the main drivers, as our society endeavours to replace a part of the fossil fuels with biofuels [7]. In addition, application of bio-syngas in FTS is attractive because biomass is the cheapest and most abundant renewable source of hydrocarbons in nature [8], and for commercial production of gasoline or diesel, the lowest cost path would be the most favourable. FTS being a versatile process by design, it has capacity to adapt to diverse feed stocks such as natural gas, coal or biomass, from which their respective names are attributed: (a) gas-to-liquid (GTL), (b) coal-to-liquid (CTL), and (c) biomass-to-liquid (BTL) processes [9]. The hydrocarbons thus produced are comparable to the conventional liquid fuels derived from crude oil when refined without containing sulphur and aromatics.

Application of plasma techniques for catalyst synthesis was initiated in the 1980s based on plasma spraying or glow discharge plasma [3]. For example, in some of the earliest works where plasma-spraying was used, five catalysts $(100 \% \mathrm{Fe}$, $75 \% \mathrm{Fe}-25 \% \mathrm{Co}, 50 \% \mathrm{Fe}-50 \% \mathrm{Co}, 25 \% \mathrm{Fe}-75 \% \mathrm{Co}$, and $100 \% \mathrm{Co}$ on $\mathrm{w} / \mathrm{w}$ percent basis) were synthesized and they showed the presence of various phases on the catalyst surface, namely, $\mathrm{Fe}$ and $\mathrm{Co}$ oxides and cemented particles of $\mathrm{CoO}-\mathrm{Fe}_{2} \mathrm{O}_{3}$ [10]. It is doubtful that such catalysts would be applicable in FTS directly without further treatment because sufficient evidence has indicated that Fe catalyzed FTS reaction mechanism depends on the presence of Fe carbides [11]. Currently in industry, the Fe carbides are generated mainly by carburizing the Fe oxides with CO [12]. By the application of induction suspension plasmaspray (SPS) technology one can generate these Fe carbides directly from the metal and carbon support, where only the excess C-matrix is gasified in order to expose the active sites to the FTS feed gas [13].

Some other authors have applied plasma pre-treatment through glow discharge to decompose Co-nitrate at much lower temperatures than conventional calcination of the Co-based FTS catalysts in order to produce smaller super paramagnetic Co metal nanoparticles of size less than $7 \mathrm{~nm}$ [14]. Since the active species for Co-based catalysts in FTS is in metallic form [15], this catalyst having shown a $26 \%$ CO conversion was found to compete favourably with the conventional Pt-promoted catalyst yielding 19-24\% CO conversion under similar reaction conditions [14]. In addition, it was observed that higher Co dispersion accompanied by ease of reducibility leads to higher catalytic activity of the plasma-treated FTS catalysts. In yet another study, plasma pre-treatment was seen to significantly enhance the Co dispersion in silica- supported catalysts and the Co-particle size was perceived to be a function of glow discharge plasma intensity, while plasma pretreatment of the Ru-promoted catalyst exhibited an enhanced FTS activity [16].

Equally, there is growing interest in the application of nonthermal plasma (NTP) reactors for FTS, which may provide viable alternatives to conventional processes that may operate with or without a catalyst. In one study, $\mathrm{C}_{1}-\mathrm{C}_{3}$ hydrocarbons were synthesized at high pressure $(\mathrm{P}>1 \mathrm{MPa})$ without a catalyst [17]. It has been shown that combining plasma with catalysts can produce new reactive species, plasma photon emissions or thermal hotspots that can initiate catalytic reactions [18]. NPT technology requires minimal space and its low cost maintenance motivates for its application. Reaction rapidity (ranging from nanoseconds to minutes) promoted by highly active NTP species at ambient temperature is one among the many advantages of the non-thermal arc discharge process [17].

The dielectric barrier discharge (DBD) plasma has been observed to promote FTS over a $\mathrm{Cu} / \mathrm{Co}$-based catalyst at low temperatures and ambient pressure. It has been shown that plasma strongly suppresses $\mathrm{CH}_{4}$ production, and, as opposed to the conventional FTS process, CO conversion in the DBDpromoted FTS was much higher at low operating pressure than at higher pressure, indicating a new FTS reaction path [19]. Several other studies reveal that plasma treatment offers many positive effects leading to higher CO conversion, lower temperature activity and better suppression of coke deposition, besides better metal dispersion, smaller $\mathrm{CO}_{3} \mathrm{O}_{4}$ cluster size, and more uniform Co distribution [20]. These results show that not only is plasma able to improve the structural properties of the catalysts, but also to enhance the reaction activity and products yield.

Current advancement in the production of synthetic fuels involve the application of induction SPS technology to produce nanometric catalysts that inherently consist of active catalytic species for FTS, that is, Fe carbides and metallic Co [13]. Therefore, the primary objective of this study was to compare different features of the FTS process, such as sample preparation methods, characterization of the catalytic properties of the materials and measurement of the performance of the catalysts. It has been shown that all catalysts produced through SPS technology (Co-only, Fe-only, Co-Fe bimetallics and those promoted with $\mathrm{Au}, \mathrm{Ni}$ and $\mathrm{Mo}$ ) consist a myriad of species and phases ranging from metallic to carbidic species. Although the relative activity of these phases is not yet quantified, all synthesized catalysts are proven to be highly active for FTS as determined from their catalytic activity and selectivity. The above described materials have been found to be nanometric and non-porous; these features lead to surface reaction kinetics, operating away from mass-diffusion controlled FTS regimes. One of the positive impacts is that, at relatively $\mathrm{H}_{2}$-poor feeds (low molar $\mathrm{H}_{2} / \mathrm{CO}$ ), the $\mathrm{CH}_{4}$ selectivity is significantly lower than with classical FTS catalysts [21]. 


\section{Recent Advances in Petrochemical Science}

With various aspects of the FTS process having been considered as shown in Figure 1, only a few areas have been examined so far due to the breadth of the subject, to which this research work has contributed new knowledge. Therefore, we begin by underscoring the major contribution SPS technology has played in the success of this work by efficiently producing highly active FTS catalysts [22]. It has been observed that the plasma method provides better catalyst composition reproducibility, which is achieved within shortened preparation time when compared to other methods such as impregnation [23], and precipitation [24]. This is mainly attributed to the fact that it is a single-step approach, producing robust catalysts whose metal components do not sinter [25]. Other authors assert that plasma methods produce materials of superior catalytic performance [26], evenly distributed active species that are characterized by longer catalyst lifetime and overall lower energy requirements $[27,28]$.

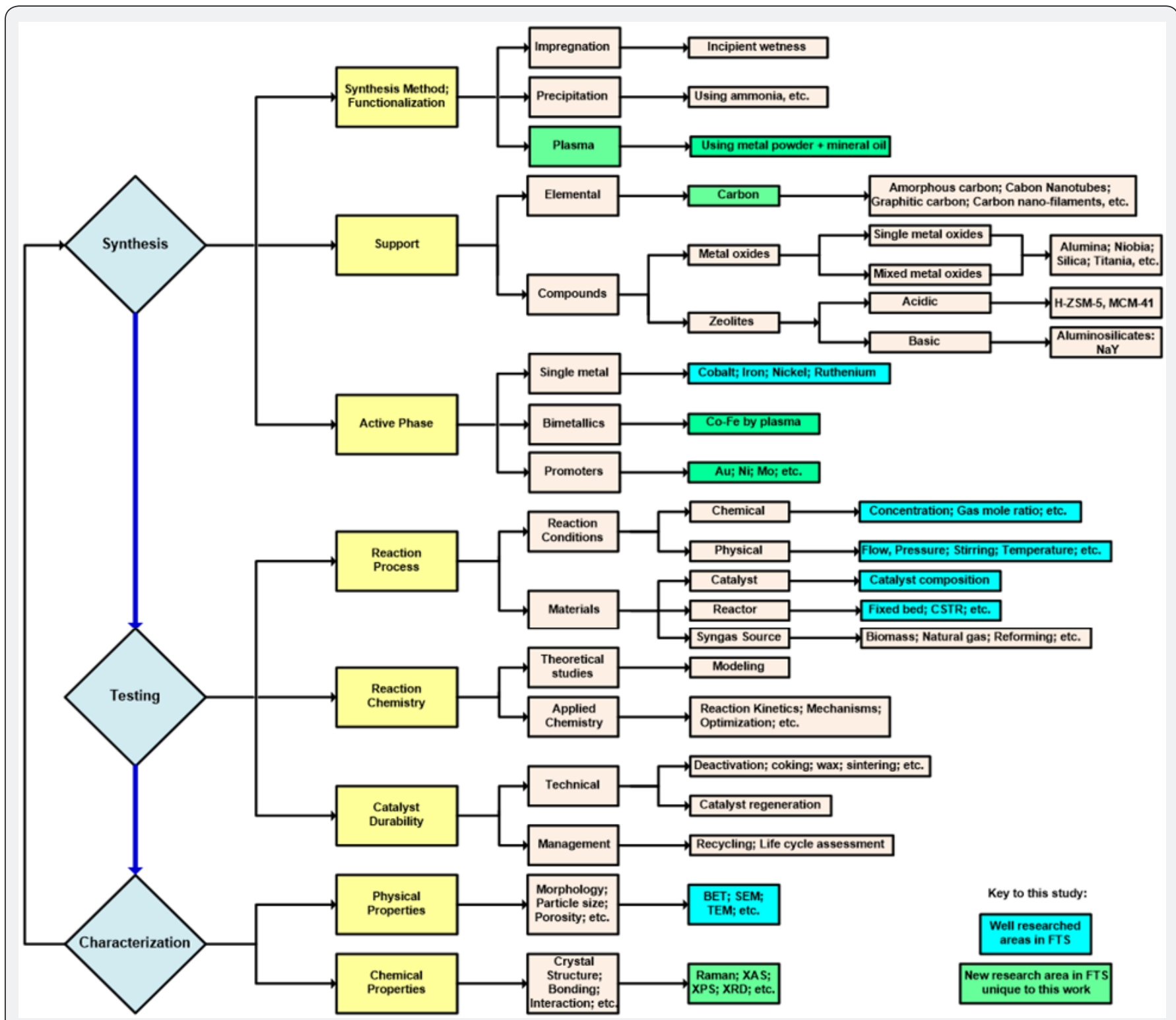

Figure 1: Global view of FTS catalysis emphasizing the areas to which this research has contributed new knowledge [28].

\section{Experimental Methods}

Using the PL-50 plasma torch supplied by Tekna Inc., the induction suspension plasma-spray (SPS) system operates at $3.2 \mathrm{MHz}$ alongside other system parameters, which are fully described in earlier works [29]. In order to enhance the production of ionic species in the plasma, radio frequency (RF) alternating currents $(\mathrm{AC})$ generate an oscillating magnetic field in a coil set around the plasma plume, which couples to the partially ionized gas flowing through the coil. The reactor set-up is provided and fully described elsewhere [22]. A homogeneous mixture of $60 \mathrm{~g}$ of the metal (particle size range $1-10 \mu \mathrm{m}$ ) in $300 \mathrm{~cm}^{3}$ of mineral oil was introduced directly into the plasma using an atomization probe at a flow rate of $8.2 \mathrm{~cm}^{3} \cdot \mathrm{min}^{-1}$ while 
maintaining the triode plate power at $29 \mathrm{~kW}$ [25]. After catalyst synthesis, the powder materials were collected from the sides of the reactor vessels and analyzed.

The FTS reaction tests were performed in a high-pressure, Autoclave Engineers (Erie, PA, U.S.A) stainless- steel vessel. This was isothermally operated as a three-phase continuous-stirred tank slurry reactor (3- $\varphi$ - CSTSR) at $220-260{ }^{\circ} \mathrm{C}$ temperature range and $2 \mathrm{MPa}$ pressure. About $5 \mathrm{~g}$ of the catalyst was used with a gas feed stock of molar $\mathrm{H}_{2}: \mathrm{CO}=2$, flowing at $300 \mathrm{~cm}^{3} \cdot \mathrm{min}^{-1}$ or gas hourly space velocity (GHSV) of about $3,600 \mathrm{~cm}^{3} \cdot \mathrm{h}^{-1} \cdot \mathrm{g}^{-1}$ of catalyst. Prior to the FTS reaction the catalysts were pre-treated in situ (because the materials are pyrophoric), at $400{ }^{\circ} \mathrm{C}$ for $24 \mathrm{~h}$ under reducing conditions of pure $\mathrm{H}_{2}$ or $\mathrm{CO}$ flowing at $250 \mathrm{~cm}^{3}$. $\mathrm{min}^{-1}$. In order to ensure that the FTS reaction operated outside diffusion limitations,

a. a nanometric catalyst was envisaged, and

b. The system was agitated with a stirring speed of over 2,000rpm. As a confirmation, an experiment doubling the mass of the catalyst to $10 \mathrm{~g}$ was performed, with an expectation that the $\mathrm{CO}$ conversion would also double. Both catalyst activity and selectivity were determined by GC analyses [30].

These catalysts were tested for FTS and found to be characteristically active:

a. Two single metal (Co/C and Fe/C) benchmarked against the commercial hematite Fe-NanoCat ${ }^{\circledR}$ [30], with the minimum testing time required to define a catalyst's $\alpha$-value determined using the Co/C sample [31].

b. Three bimetallic formulations (30\%Co-70\% Fe $/ \mathrm{C}$, $50 \% \mathrm{Co}-50 \% \mathrm{Fe} / \mathrm{C}$ and $80 \% \mathrm{Co}-20 \% \mathrm{Fe} / \mathrm{C}$ ) tested after reduction in $\mathrm{H}_{2}$ or $\mathrm{CO}$ [32].

c. Two ternary formulations simulating promotion of the $80 \% \mathrm{Co}-20 \% \mathrm{Fe} / \mathrm{C}$ sample (10\%Mo-70\%Co- $20 \% \mathrm{Fe} / \mathrm{C}$ and $10 \% \mathrm{Ni}-70 \% \mathrm{Co}-20 \% \mathrm{Fe} / \mathrm{C}$ ) and in this discourse are abbreviated as $\mathrm{Mo}-\mathrm{Co}-\mathrm{Fe} / \mathrm{C}, \mathrm{Ni}-\mathrm{Co}-\mathrm{Fe} / \mathrm{C}$ respectively [33].

d. The $5 \% \mathrm{Ni}-70 \% \mathrm{Co}-25 \% \mathrm{Fe} / \mathrm{C}$, which was later promoted with $\sim 5 \%$ Au doping, (abbreviated as Au- Ni-Co-Fe/C).

All the single metal, bimetallic and ternary metal formulations have been fully characterized for their specific surface areas by the Brunauer-Emmett-Teller (BET) method, metal particle dispersion and analysis for particle size distribution has been conducted using transmission electron microscopy (TEM) [22]. Scanning electron microscopy (SEM), coupled with the energy dispersive X-ray spectroscopy (EDX) was used to confirm metal particle dispersion in the C-matrix by EDX-mapping [22]. Phase identification and quantification has been attempted using powder X-ray diffraction ( $\mathrm{p}$-XRD) analysis in conjunction with Rietveld quantitative analysis (RQA) [30], with catalyst evaluation results by X-ray photoelectron spectroscopy (XPS) and X-ray absorption near-edge structure (XANES) confirming some of the XRD data [25].

\section{Results and Discussion}

Plasma applications are currently receiving a lot of attention because, when viewed in the broader context of global technology trends, they continue to find new industrial applications in materials processing including the development of commercial catalysts [34]. In this work, we show that FTS catalysts produced through SPS technology were both nanometric and non-porous. Since nanometric catalysts are imperative in overcoming mass transfer limitations in the FTS process, the aim was to produce both the active phase (containing the metallic moieties) and the carbon support of different forms (the disordered, D and the graphitic, G) in the nanometric range.

The use of plasma is therefore an attempt to produce high quality catalysts by means of a less complex method. After method optimization with the Fe-only FTS catalytic formulation, the same recipe was applied with the same success for all other catalyst formulations. This preserves the distinct qualities of the materials despite variation in metal composition. In addition, having the catalysts supported on nanometric carbon, no adverse effects have been observed in the catalyst performance so far, although deactivation by $\mathrm{C}$ deposition is rampant in most FTS catalysts, which means that not all forms of carbon lead to deactivation [35]. Therefore, catalyst synthesis through plasma presents a unique way of producing high quality FTS catalysts, with potential for commercialization.

\section{Catalyst characterization}

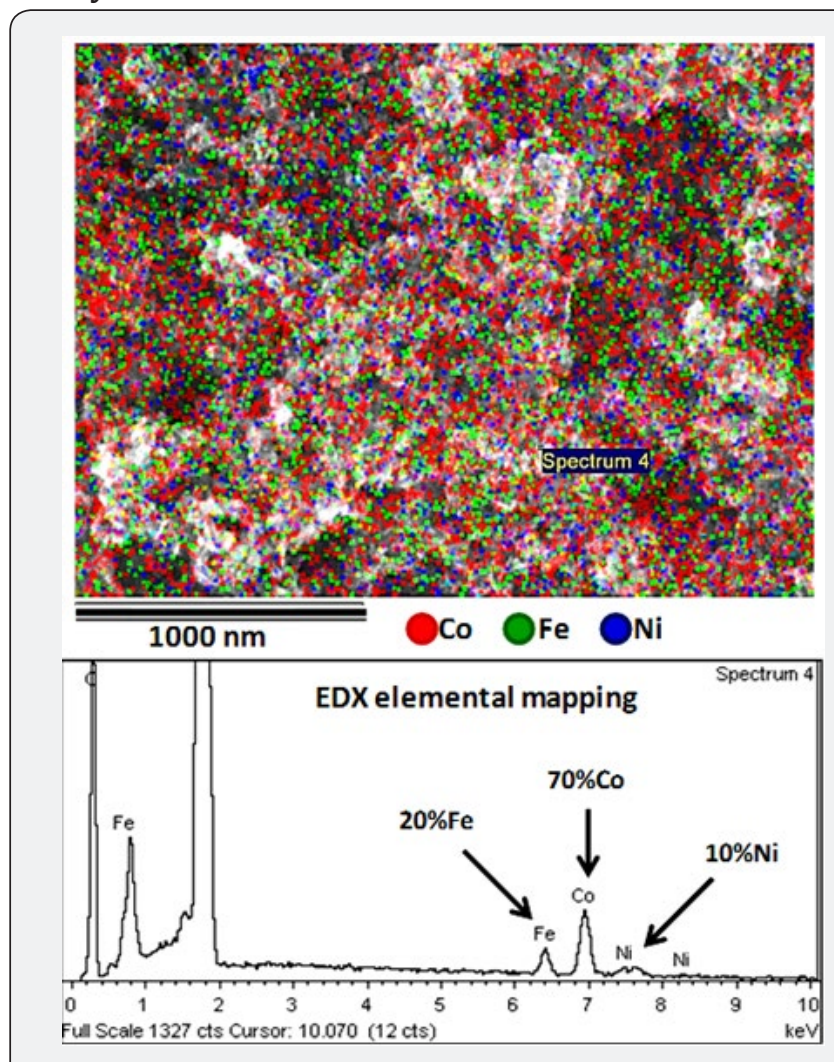

Figure 2: SEM imaging by EDX mapping showing the elemental analysis of a plasma-synthesized $\mathrm{Ni}-\mathrm{Co}-\mathrm{Fe} / \mathrm{C}$ sample. 
BET surface area analysis: The plasma-synthesized materials were analyzed and found to have BET specific surface area in the range of $35-93 \mathrm{~m}^{2} \cdot \mathrm{g}^{-1}$, with the single-metal catalysts having the lowest surface areas [22]. The catalysts were also shown to be non-porous from their characteristic overlaid adsorption and desorption isotherms, which is advantageous because it enables the FTS reaction to operate away from mass transfer limitations.

Scanning electron microscopy: SEM imaging portrayed high metal dispersion in the C-matrix, attesting to the high quality of the materials synthesized by plasma. Figure 2 indicates that there was no preferential metal deposition or metal segregation because of the apparent uniform distribution of the all the three metals across the C-matrix.

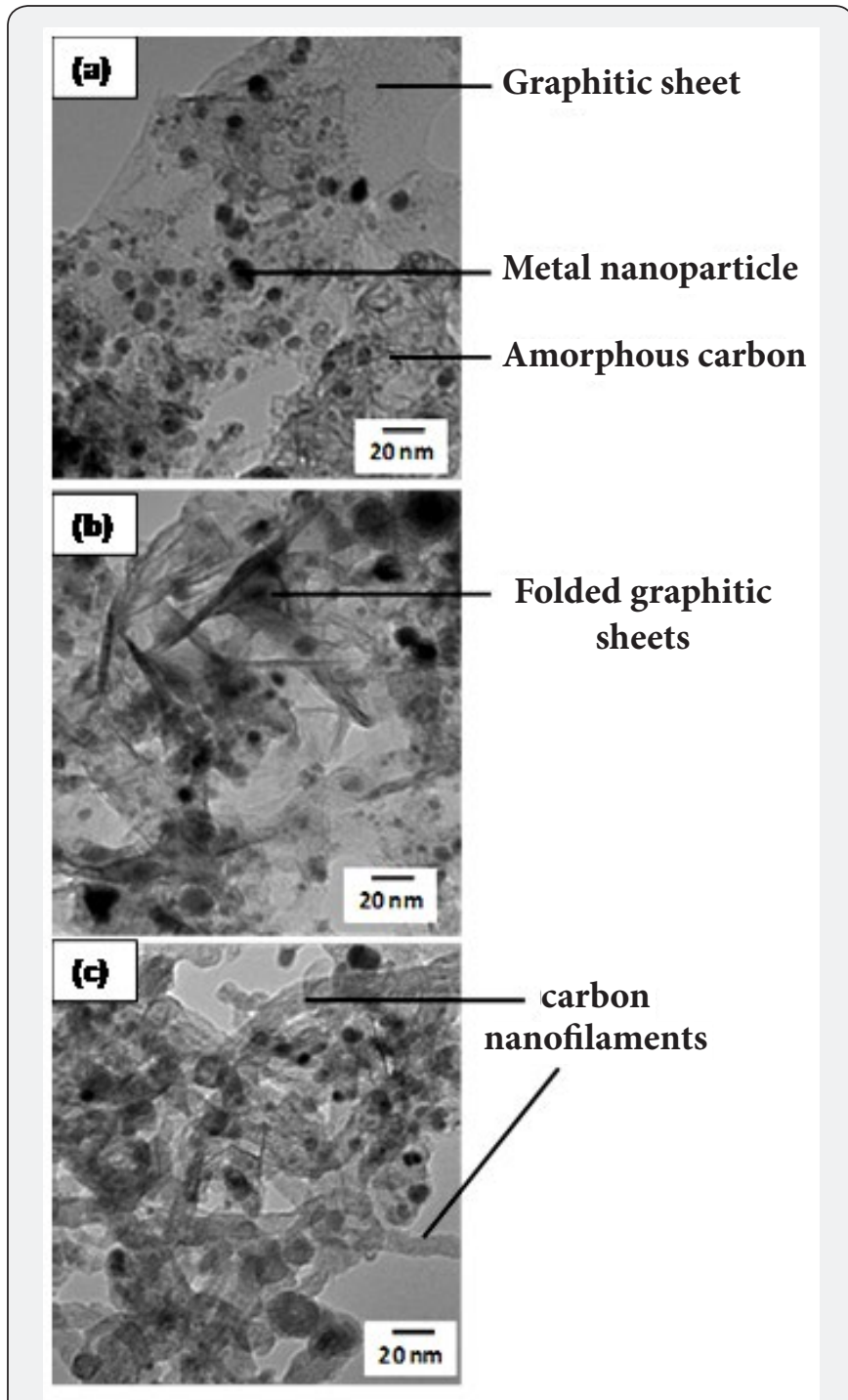

Figure 3: TEM analysis of the (a) fresh Co/C sample; (b) $\mathrm{H}_{2}-$ reduced $\mathrm{Co} / \mathrm{C}$ sample after FTS; and (c) CO-reduced $30 \% \mathrm{Co}-$ $70 \% \mathrm{Fe} / \mathrm{C}$ sample after FTS

Transmission electron microscopy: TEM analysis indicated consistent particle-size distribution and that both the fresh and used single-metal $\mathrm{Co} / \mathrm{C}$ and $\mathrm{Fe} / \mathrm{C}$ catalysts had a mean particle of $\sim 9 \mathrm{~nm}$ [30]. The $80 \% \mathrm{Co}-20 \% \mathrm{Fe} / \mathrm{C}$ and $30 \% \mathrm{Co}-70 \% \mathrm{Fe} / \mathrm{C}$ bimetallic samples had mean of $\sim 11 \mathrm{~nm}$, but only the $50 \%$ Co$50 \% \mathrm{Fe} / \mathrm{C}$ sample was unique with a much higher mean of $\sim 14 \mathrm{~nm}$, possibly because it contained more CoFe nano-alloys [32]. Figure $3 \mathrm{a} \& 3 \mathrm{~b}$ indicates that there was very little difference in the catalyst's morphology after conducting the FTS reaction except for the augmented creasing of the graphitic sheets, although there was very little evidence to show any major change in the metal particle size during FTS reaction [30], particularly when $\mathrm{H}_{2}$ was used for catalyst activation. However, with $\mathrm{CO}$ reduction, the C-matrix in Fe-containing samples converted into carbon nanofilaments and this is exemplified in Figure 3c [32].

X-ray diffraction analysis: XRD analysis in conjunction with RQA gave some indication of the phases present in the samples although the materials being amorphous made absolute quantification difficult. As seen in Figure 4, XRD identified easily both the metallic species and graphitic-C. However, confirmation of carbide species by other techniques such as XPS was difficult though they were detected by XRD. For example, in the singlemetal samples, the presence of Fecarbides $\left(\mathrm{Fe}_{2} \mathrm{C}, \mathrm{Fe}_{3} \mathrm{C}, \mathrm{Fe}_{5} \mathrm{C}_{2}\right)$ was recognized in the $\mathrm{Fe} / \mathrm{C}$ and possibility of Cocarbides $\left(\mathrm{Co}_{2} \mathrm{C}\right.$, $\mathrm{Co}_{3} \mathrm{C}$ ) was high in the $\mathrm{Co} / \mathrm{C}$ [30], but XPS could not detect these carbides [25]. In addition, the same carbide species were perceived in the bimetallic $\mathrm{Co}-\mathrm{Fe} / \mathrm{C}$ formulations, but in small quantities alongside nano-alloys such as $\mathrm{CoFe}, \mathrm{Co}_{3} \mathrm{Fe}_{7}$ and $\mathrm{Co}_{7} \mathrm{Fe}_{3}$ [32].

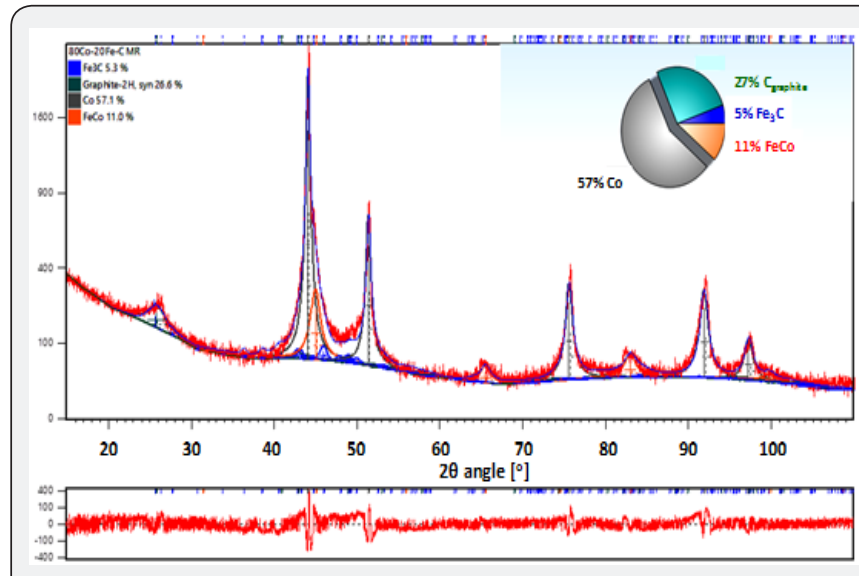

Figure 4: XRD pattern of the fresh bimetallic $80 \% \mathrm{Co}-20 \% \mathrm{Fe} / \mathrm{C}$ catalyst showing possible phase concentrations by RQA [28].

\section{Catalyst activity testing}

Initial FTS catalyst activity was recorded with time-on-stream (TOS) for over $25 \mathrm{~h}$ by sweeping over a range of temperatures, as shown in Figure 5. Using the single metal Co/C catalyst, the average activity was shown to be about $40 \%$ CO conversion at $220{ }^{\circ} \mathrm{C}, 50 \%$ CO conversion at $230{ }^{\circ} \mathrm{C}$, over $65 \%$ CO conversion at $240{ }^{\circ} \mathrm{C}$, and total $\mathrm{CO}$ conversion at $260{ }^{\circ} \mathrm{C}$. Since the catalysts proved to be highly active, rapid consumption of the feedstock gases produced significant pressure drops and temperature spikes that led to significant fluctuations in readings. Figure 6 was a reproducibility test, where four different samples of the same $(\mathrm{Co} / \mathrm{C})$ catalyst were reduced and tested separately for 
FTS, and all the data points were averaged, with the overall activity found to be about $41 \% \mathrm{CO}$ conversion at $220{ }^{\circ} \mathrm{C}, 2 \mathrm{MPa}$ pressure and GHSV of $3,600 \mathrm{~cm}^{3} \cdot \mathrm{h}^{-1} \cdot \mathrm{g}^{-1}$ of catalyst. The scatter of the data points indicated a standard deviation, $(\sigma)$ of $3 \%$.

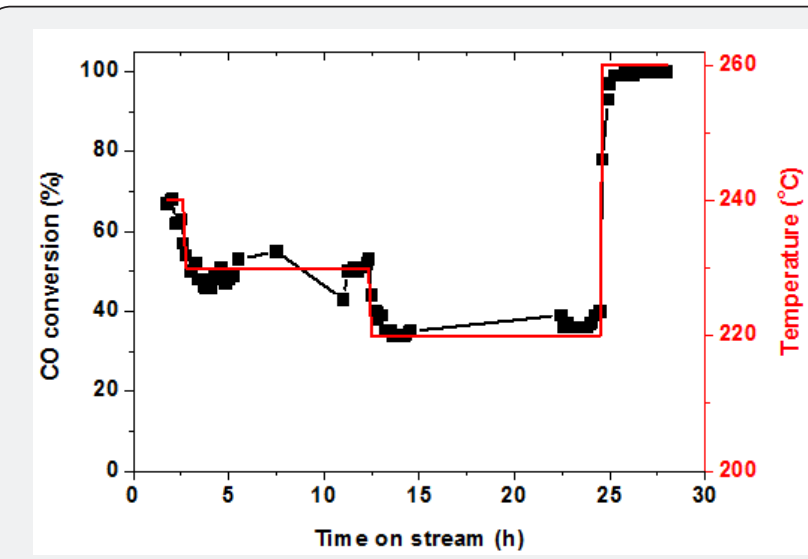

Figure 5: Activity plot showing $\mathrm{CO}$ conversion at various temperatures $\left(220-260{ }^{\circ} \mathrm{C}\right), 2 \mathrm{MPa}$ and $\mathrm{GHSV}=3,600 \mathrm{~cm}^{3} \cdot \mathrm{h}^{-1} \cdot \mathrm{g}^{-1}$ of $\mathrm{Co} / \mathrm{C}$ catalyst.

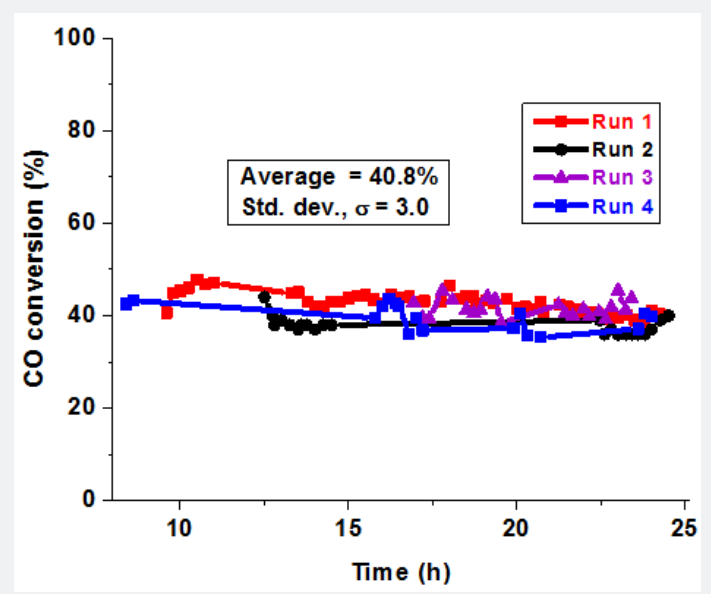

Figure 6: Activity plots of the $\mathrm{Co} / \mathrm{C}$ catalyst showing $\mathrm{CO}$ conversion with TOS at $220^{\circ} \mathrm{C}, 2 \mathrm{MPa}$ and $\mathrm{GHSV}=3,600 \mathrm{~cm}^{3} \cdot \mathrm{h}^{-1} \cdot \mathrm{g}^{-1}$

In order to confirm that the reaction was operated outside diffusion limitations, doubling the catalyst mass to $10 \mathrm{~g}$ (GHSV of $1,800 \mathrm{~cm}^{3} \cdot \mathrm{h}^{-1} \cdot \mathrm{g}^{-1}$ of catalyst) increased its activity by almost double to $78 \%$ CO conversion. The main reason for operating away from diffusion-limited regimes is that FTS is a polymerization reaction and the inevitable formation of the heavier molecular weight and longer hydrocarbon chains with TOS eventually lead to catalyst deactivation due to clogging of the catalyst pores. This observation assists in determining the catalyst's lifespan and possibly the cause of its activity loss with TOS. In our case, catalyst activity seemed to be stable in the first $24 \mathrm{~h}$. The Co/C catalyst was observed to be the most active catalyst, followed by the $\mathrm{Fe} / \mathrm{C}$ catalyst in comparison to the bimetallic $\mathrm{Co}-\mathrm{Fe} / \mathrm{C}$ formulations [32]. In addition, catalyst activation by $\mathrm{H}_{2}$ reduction was perceived to produce more active materials than those activated by $\mathrm{CO}$ reduction, while Ni-addition to the bimetallic Co-Fe/C catalyst enhanced its activity from 42 to $50 \%$
CO conversion [33], but Mo-addition slightly depressed catalyst activity to $38 \%$.

It is advanced that during synthesis, plasma produced nanoalloy species (such as $\mathrm{CoFe}, \mathrm{Co}_{3} \mathrm{Fe}_{7}$ and $\mathrm{Co}_{7} \mathrm{Fe}_{3}$ ) in the bimetallic samples (as established from RQA and XRD analysis), which seem to be less available for FTS, thus leading to lower catalytic activity. This may be related to the inactive portion of the material being mixed with an active metal, resulting in some degree of dilution of the more active metal phase [36]. Although various studies demonstrate an inconsistent stability behaviour of bimetallic catalysts towards their activity, selectivity and deactivation [37], higher CO conversion was observed with increasing Fe content up to $0.5 \mathrm{wt} \%$ for CoFe supported on carbon nanotubes [38]. Alloying Co with $\mathrm{Ni}$, for example, has been shown to be effective in enhancing the CO hydrogenation activity [39]. For the Fe-Co/ $\mathrm{SiO}_{2}$ systems, higher activity was observed in the Co-rich system [36], while the presence of small amounts of CoFe alloys was also related to an increased selectivity for alcohols [38]. However, the overall activity for the bimetallic systems, decreases with an increase in Fe content [36].

In Fe-catalyzed FTS, carbides are viewed to be the most active species because a process that replenishes them seems to enhance the reaction [40]. However, some controversy persists because one school thought asserts that both magnetite and metallic Fe are active for FTS, while the carbides are inactive. Yet another school of thought advances that WGS reaction occurs on magnetite sites, while FTS takes place on the carbide sites [41]. Other authors claim that the non-stoichiometric Fe-oxidecarbide complex is the active phase [42]. Nevertheless, original findings from the use of SPS technology in catalyst synthesis demonstrated the benefit of plasma method in creating the Fe-carbides, which are thought to be indispensable in FTS [13]. Although the FTS reaction mechanism remains unclear, production of carbides partly guided the decision for catalyst choice, supported by C-material such as graphite [43]. Despite these differences in opinion, it is our view that these nano-alloys do not play a crucial role in FTS.

\section{Catalyst selectivity}

From the initial studies carried out using the single-metal catalysts, it was shown that the plasma- synthesized Co/C catalyst was more selective towards the formation of longerchain hydrocarbons, with massive waxes being displayed [30]. The kinetics of the FTS reaction involve the catalyst's alpha value $(\alpha)$, which denotes the probability for hydrocarbon-chain growth [44], and the prediction is expressed in the form of the Anderson-Schulz-Flory (ASF) distribution given by Equation (2) below [45].

$$
\frac{M_{n}}{n}=(1-\alpha)^{2} \cdot \alpha^{(n-1)}
$$


Where: $\mathrm{M}_{\mathrm{n}}=$ mole fraction of a hydrocarbon with chain length $n$

$\mathrm{n}=$ number of total carbon atoms

$\alpha=$ probability of chain growth $(\alpha<1)$

$(1-\alpha)=$ probability of chain termination

The $\alpha$-value of the Co/C catalyst (for $n>10$ ), was found to be in the range of 0.8-0.9 depending on the feedstock composition, where the CO-rich feed gas mimicking a bio-syngas source registered a higher value [31] (Figure 7). On the other hand, the plasma-synthesized $\mathrm{Fe} / \mathrm{C}$ catalyst formed less waxes, but showed an identical $\alpha$-value of over 0.8 , which sharply contrasts with the commercial nano-hematite, Fe-NanoCat ${ }^{\circledR}$ that had an $\alpha$-value of 0.7 as expected. Normally, the $\alpha$-value for Co lies in the range of $0.7-0.8$, while Fe operates between $0.5-0.7$ [46].

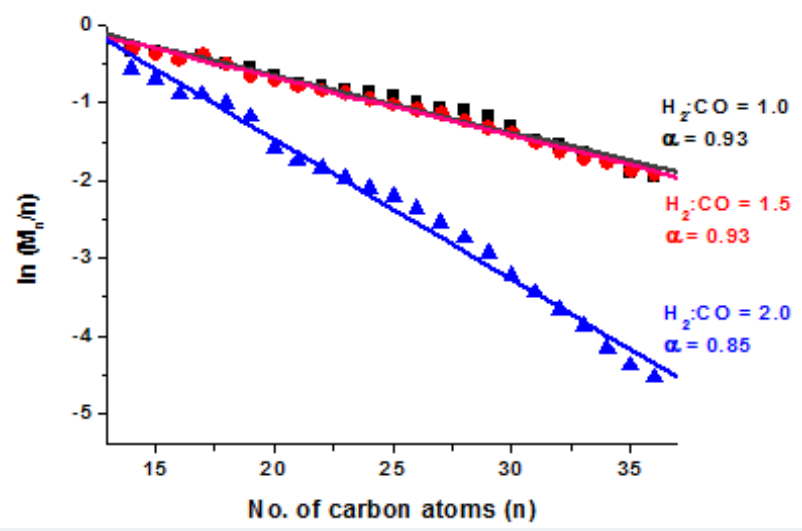

Figure 7: High $\alpha$-values for CO-rich feed gases, and low $\alpha$-values for $\mathrm{H}_{2}$-rich feed gases in the $\mathrm{Co} / \mathrm{C}$ catalyst tested at 493K, 2MPa [31].

Figure 8 shows that by targeting for metal nanoparticles of mean size of approximately $10 \mathrm{~nm}$ in plasma-synthesized catalysts, the materials would produce more of the longer-chain hydrocarbons than gasoline fraction because the smaller the catalyst, the higher it's $\alpha$-value [47]. Usually, high $\alpha$-values at low temperature favour production of diesel and high molecularmass hydrocarbons (e.g. waxes), with less of gasoline and low molecular-weight compounds. Table 1 provides a summarized selectivity analysis of other catalysts.

Table 1: FTS reaction conditions of $\mathrm{H}_{2}: \mathrm{CO}$ ratio $=2.0$, pressure $2.0 \mathrm{MPa}$

\begin{tabular}{|c|c|c|c|c|c|c|}
\hline \multirow[t]{2}{*}{ Catalyst } & \multirow[t]{2}{*}{ Particle Size (nm) } & \multirow[t]{2}{*}{ Temperature $\left({ }^{\circ} \mathrm{C}\right)$} & \multicolumn{3}{|c|}{ Fuel Product Fractions (F) } & \multirow[t]{2}{*}{ Data Source (Ref.) } \\
\hline & & & Gasoline $\left(\mathrm{F}_{\mathrm{G}}\right)$ & Diesel + Waxes $\left(F_{D+W}\right)$ & $\left(F_{D+W}\right) /\left(F_{G}\right)$ & \\
\hline Co/C & 11.0 & 220 & 29.8 & 65.7 & 2.2 & {$[31]$} \\
\hline $\mathrm{Fe} / \mathrm{C}$ & 11.3 & 220 & 25.6 & 69.0 & 2.7 & {$[30]$} \\
\hline Fe-Nano Cat ${ }^{\circledR}$ & 21.1 & 220 & 62.2 & 31.6 & 0.5 & {$[30]$} \\
\hline $80 \% \mathrm{Co}-20 \% \mathrm{Fe} / \mathrm{C}$ & 8.9 & 260 & 19.1 & 67.2 & 3.5 & {$[32]$} \\
\hline $30 \% \mathrm{Co}-70 \% \mathrm{Fe} / \mathrm{C}$ & 9.1 & 260 & 29.0 & 55.0 & 1.9 & {$[32]$} \\
\hline $\mathrm{Co} / \mathrm{C}$ & 11.0 & 260 & 8.6 & 23.8 & 2.8 & {$[32]$} \\
\hline $\mathrm{Fe} / \mathrm{C}$ & 11.3 & 260 & 19.4 & 63.9 & 3.3 & {$[32]$} \\
\hline $50 \% \mathrm{Co}-50 \% \mathrm{Fe} / \mathrm{C}$ & 14.4 & 260 & 48.9 & 32.1 & 0.7 & {$[32]$} \\
\hline
\end{tabular}


Currently, there is a growing interest in understanding the dependency of FTS activity and selectivity on catalyst particle size, but the origin of the particle size effect in FTS remains controversial because of the complexity of the reaction's kinetics and mechanisms [48]. This is in addition to the limitations of in situ characterization set-ups, which can hardly operate at both high temperature and high pressure while simultaneously allowing for real time analysis of the FTS products. From Table 1, it can be concluded that:

(a). Our high mean particle size catalysts (e.g. 14 or 21 $\mathrm{nm}$ ) produced more gasoline, with the ratio of the heavy molecules to the light ones, $\left(\mathrm{F}_{\mathrm{D}+\mathrm{W}}\right) /\left(\mathrm{F}_{\mathrm{G}}\right)$ being lower than 1 .

(b). Our lower mean particle size catalysts $(\sim 10 \mathrm{~nm})$ produced more longer-chain hydrocarbons and the ratio $\left(F_{D+W}\right) /\left(F_{G}\right)$ was about 2 and above, regardless of the catalyst composition.

The above results seem to confirm the idea that FTS is a "structure sensitive" reaction since other studies have indicated that within a size range of $3-10 \mathrm{~nm}$, a catalyst (Fe/SBA-15) with higher crystal size presented higher conversion, higher chain growth and lower $\mathrm{CH}_{4}$ production [49]. In addition, selectivity also has been seen to be considerably dependent on the metal particle size in Co-based FTS catalysts, and the smaller the particle, the higher the probability of producing longer-chain hydrocarbons [47]. However, the literature reports that smaller Co particles (typically $<7 \mathrm{~nm}$ ) show low turnover frequency that is attributed to stronger $\mathrm{CO}$ adsorption [50]. Other authors concur that metal nanoparticles smaller than $6 \mathrm{~nm}$ lead to both poor activity and inferior selectivity towards the $\mathrm{C}_{5+}$ fractions [43]. These studies bring to the fore the significant role nanometric materials will play in the future of FTS catalysis. Although some authors have observed that Co particularly remains in the metallic state under FTS conditions [51], often the catalyst composition changes with TOS, but our plasmasynthesized samples have not shown any sign of degradation so far. This conclusion is drawn from the comparative analysis of the fresh and used catalysts by TEM imaging where there was hardly any change in the particle size distribution [30], and from XRD analysis, see Figure 9 [32].

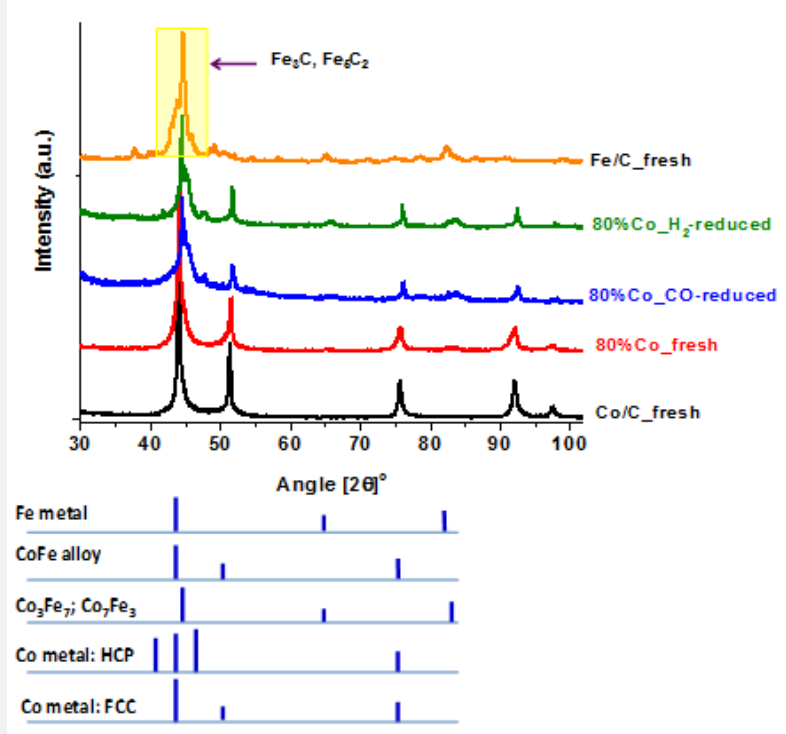

Figure 9 : Sample XRD patterns of the fresh $\mathrm{Co} / \mathrm{C}, \mathrm{Fe} / \mathrm{C}$ and $80 \% \mathrm{Co}-20 \% \mathrm{Fe} / \mathrm{C}$ catalysts compared to the used $80 \% \mathrm{Co}-20 \% \mathrm{Fe} / \mathrm{C}$ after FTS using either $\mathrm{H}_{2}$ or $\mathrm{CO}$ reduction

The effect of pre-treatment medium was also investigated: depending on catalyst composition, the CO-reduced catalysts showed enhanced selectivity for diesel fraction (50-67\%) than catalysts reduced in $\mathrm{H}_{2}$ (45-55\%) [32]. In addition, it was observed that catalysts containing high concentration of Co as well as those reduced in $\mathrm{H}_{2}$ generated more $\mathrm{H}_{2} \mathrm{O}$ than those reduced in CO. Further, the presence of $\mathrm{Au}$ (that is, in Ni-Co$\mathrm{Fe} / \mathrm{C}$ ) not only lowered the activity of the Ni-Co-Fe/C catalyst, but it also lowered its capacity to form $\mathrm{H}_{2} \mathrm{O}$, although it had no significant impact on the catalyst's hydrocarbon selectivity [52]. Therefore, the ternary systems were found to be better at $\mathrm{H}_{2}$ utilization since they incorporated most of the $\mathrm{H}_{2}$ to produce hydrocarbons rather than forming FTS by-products such as $\mathrm{H}_{2} \mathrm{O}$, and the Mo-Co-Fe/C catalyst being the best at $\mathrm{H}_{2}$ utilization efficiency [33].

Enriching the catalyst-surface acidity by Mo-promotion of the $\mathrm{Co}-\mathrm{Fe} / \mathrm{C}$ bimetallic sample improved selectivity for both gasoline fraction (from 19 to $33 \%$ ) and the overall fuel $\mathrm{C}_{5}-\mathrm{C}_{20}$ fraction (from 74 to $87 \%$ ). This lowered $\mathrm{H}_{2} \mathrm{O}$ production by $30 \%$, although at lower CO conversion $(\sim 38 \%)$. Moreover, $\mathrm{Ni}-$ addition to the $\mathrm{Co}-\mathrm{Fe} / \mathrm{C}$ bimetallic sample enhanced catalyst activity from $\sim 42$ to $50 \%$ CO conversion, and boosted selectivity towards gasoline fraction $\left(\mathrm{C}_{5} \mathrm{C}_{12}\right)$ from $\sim 19$ to $50 \%$. The catalysts' $\alpha$-values were $\sim 0.8$ in the $\mathrm{C}_{10+}$ region, and from mass 
balance, their estimated $\mathrm{H}_{2}$ efficiency decreased in the order of Mo-Co-Fe/C >> Co-Fe/C > Ni-Co-Fe/C. A summary of the plots is provided in Figure 10. Overall, the Co-Fe bimetallics and the acidified Co-Fe catalyst (i.e. Mo-Co-Fe/C) were more selective towards diesel formation ( 55\%) [53].

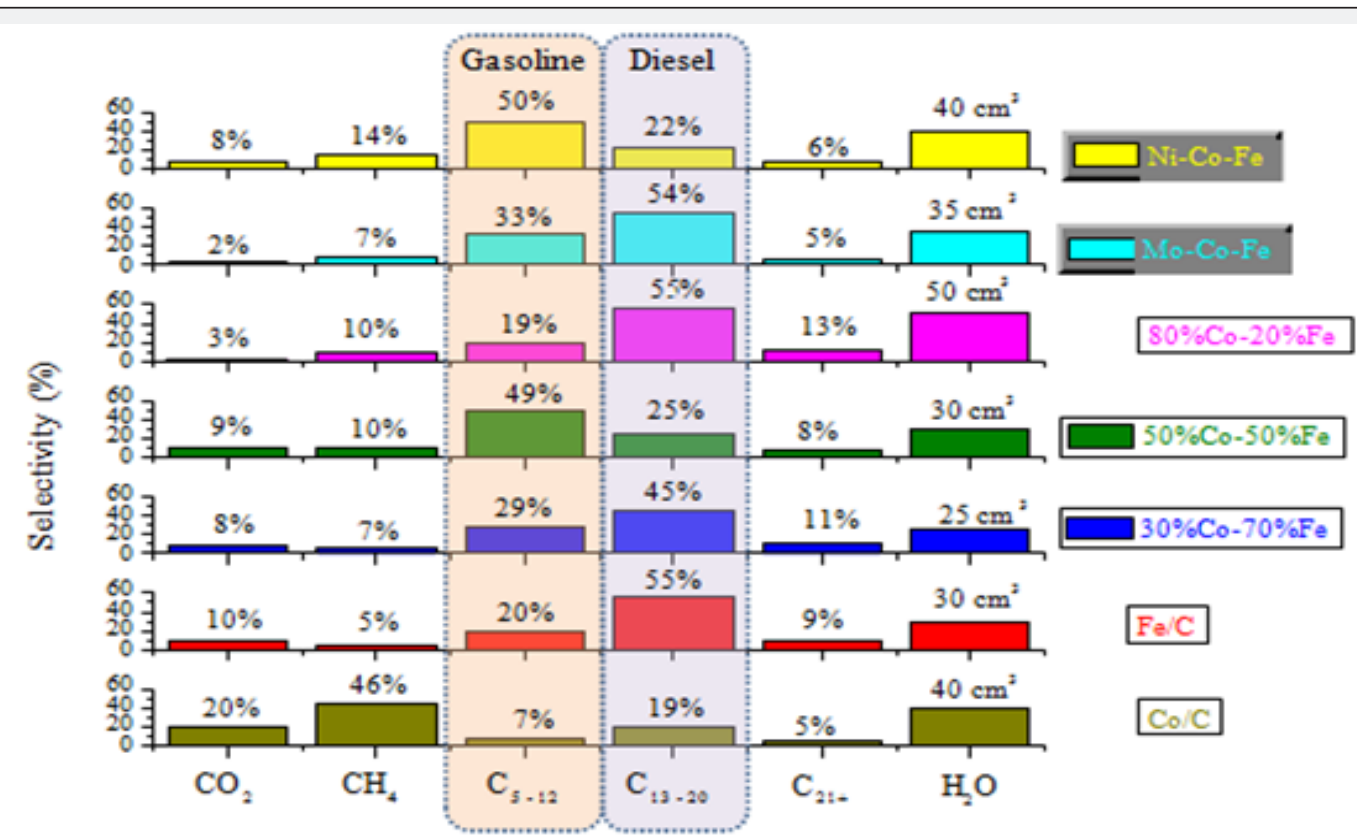

Figure 10: FTS product distribution of the plasma-synthesized single-metal, bimetallic and ternary formulations tested at $260{ }^{\circ} \mathrm{C}, 2 \mathrm{MPa}, \mathrm{GHSV}=$ $3,600 \mathrm{~cm}^{3} \cdot \mathrm{h}^{-1} \cdot \mathrm{g}^{-1}$ of catalyst [53].

\section{Conclusion}

Plasma technology presents a relatively new approach in catalyst synthesis, and when fully developed, it will offer new processing routes with higher overall efficiency in commercial materials processing. Its potential has already been demonstrated in both thermal and non-thermal plasma applications, and it might play a central role in the commercial production of synthetic fuels through Fischer-Tropsch catalysis. Being a single-step process, SPS technology opens prospects for higher energy-efficient, more productive, and environmentally greener processes. In our study, nanometric C-supported catalysts based on Co and Fe with various metal formulations were synthesized through high temperature plasma. The active catalytic species of the metals and the C-matrix support composing both graphitic $(\mathrm{G})$ and amorphous (D; disordered) carbon were all simultaneously generated in situ within the plasma.

With our differently selected chemical compositions, all the catalysts synthesized were tested and found to be highly active for FTS under various reaction conditions. For example, the Co/C catalyst being the most active, indicated $\sim 40 \%$ CO conversion at $220{ }^{\circ} \mathrm{C}, 2 \mathrm{MPa}$ pressure, and GHSV $=3,600 \mathrm{~cm}^{3} \cdot \mathrm{h}^{-1} \cdot \mathrm{g}^{-1}$ of catalyst. The catalyst showed high selectivity towards the longer hydrocarbon chains with $30 \%$ gasoline $\left(\mathrm{C}_{5}-\mathrm{C}_{12}\right), 45 \%$ diesel $\left(\mathrm{C}_{13}-\mathrm{C}_{20}\right)$, and $21 \%$ waxes $\left(\mathrm{C}_{21+}\right)$, less than $4 \% \mathrm{CH}_{4}$ and trace amounts of $\mathrm{CO}_{2}$. Other catalysts tested include $\mathrm{Fe} / \mathrm{C}$, bimetallic $\mathrm{Co}-\mathrm{Fe} / \mathrm{C}$ formulations and those promoted with $\mathrm{Ni}, \mathrm{Mo}$, and $\mathrm{Au}-$
Ni. It is currently thought that among other factors that influence FTS when using plasma-synthesized catalysts, particle size takes precedence regardless of composition. This is because those catalysts with smaller particles (mean size range of 9-11nm) were more selective towards the formation of diesel fraction and waxes than those with larger particles of mean size of $14-21 \mathrm{~nm}$ that produce more gasoline.

\section{Acknowledgements}

We thank the Bio Fuel Net National Center of Excellence -Canada and the National Science \& Engineering Research Council of Canada for financial support; Dr. Kossi Béré for technical support on the Plasma reactor system; Henri Gauvin and Jacques Gagné for technical support on the FischerTropsch reactor system; the CCM (Centre de Caractérisation des Matériaux, Université de Sherbrooke) staff for facilitating the characterization: Irène Kelsey Lévesque and Carl St.-Louis for BET surface area analysis, Charles Bertrand for Microscopy (SEM \& TEM), and Stéphane Gutierrez for XRD analysis.

\section{References}

1. Dry ME (2002) The Fischer-Tropsch process: 1950-2000. Catal Today 71(3-4): 227-241.

2. Dry ME (1990) Fischer-Tropsch synthesis over iron catalysts. Catal Lett $7(1-4): 241-252$.

3. Khodakov AY, Chu W, Fongarland P (2007) Advances in the development of novel cobalt Fischer-Tropsch catalysts for synthesis of long-chain hydrocarbons and clean fuels. Chem Rev 107(5): 1692-1744. 
4. Fechete I, Wang Y, Védrine JC (2012) The past, present and future of heterogeneous catalysis. Catal Today 189(1): 2-27.

5. Schulz H (1999) Short history and present trends of Fischer-Tropsch synthesis. Appl Catal A 186(1-2): 3-12.

6. Mawhood RK, Gazis E, Hoefnagels R, Jong SD, Slade R, et al. (2015) Technological and commercial maturity of aviation biofuels: Emerging options to produce jet from lignocellulosic biomass. Paper presented at the $14^{\text {th }}$ International Conference on Sustainable Energy Technologies SET $2015\left(25^{\text {th }}-27^{\text {th }}\right.$ of August 2015), Nottingham, UK.

7. Chew TL, Bhatia S (2008) Catalytic processes towards the production of biofuels in a palm oil and oil palm biomass-based biorefinery. Bioresour Technol 99(17): 7911-7922.

8. Jahangiri H, Bennett J, Mahjoubi P, Wilson K, Gu S, et al. (2014) A review of advanced catalyst development for Fischer-Tropsch synthesis of hydrocarbons from biomass derived syn-gas. Catal Sci Technol 4(8): 2210-2229.

9. Klerk DA, Furimsky E (2011) Catalysis in the Refining of FischerTropsch Syncrude. Platin Met Rev 55(4): 263-267.

10.Dalai AK, Bakhshi NN, Esmail MN (1992) Characterization studies of plasma-sprayed cobalt and iron catalysts. Ind Eng Chem Res 31(6): 1449-1457.

11. Bengoa JF, Alvarez AM, Cagnoli MV, Gallegos NG, Marchetti SG, et al (2007) Influence of intermediate iron reduced species in FischerTropsch synthesis using Fe/C catalysts. Appl Catal A 325(1): 68-75.

12. Ding M, Yang Y, Wu B, Xu J, Zhang C, et al. (2009) Study of phase transformation and catalytic performance on precipitated iron-based catalyst for Fischer-Tropsch synthesis. J Mol Catal A: Chem 303(1-2) 65-71.

13. Blanchard J, Abatzoglou N, Eslahpazir-Esfandabadi R, Gitzhofer F (2010) Fischer-Tropsch synthesis in a slurry reactor using a nano-iron carbide catalyst produced by a plasma spray technique. Ind Eng Chem Res 49(15): 6948-6955.

14. Chu W, Wang LN, Chernavskii PA, Khodakov AY (2008) Glow-discharge plasma-assisted design of cobalt catalysts for Fischer-Tropsch synthesis. Angew Chem Int Ed 47(27): 5052-5055.

15. Jacobs G, Ma W, Gao P, Todic B, Bhatelia T, et al. (2013) The application of synchrotron methods in characterizing iron and cobalt Fischer-Tropsch synthesis catalysts. Catal Today 214: 100-139.

16. Hong J, Chu W, Chernavskii PA, Khodakov AY (2010) Cobalt species and cobalt-support interaction in glow discharge plasma-assisted FischerTropsch catalysts. J Catal 273(1): 9-17.

17. Govender BB, Iwarere SA, Ramjugernath D (2017) The application of non-thermal plasma catalysis in Fischer-Tropsch Synthesis at very high pressure: The effect of cobalt loading. Paper presented at the World Congress on Engineering and Computer Science (WCECS 2017), San Francisco, USA.

18. Durme VJ, Dewulf J, Leys C, Langenhove VH (2008) Combining nonthermal plasma with heterogeneous catalysis in waste gas treatment: A review. Appl Catal B 78(3-4): 324-333.

19.Al-Harrasi WSS, Zhang K, Akay G (2013) Process intensification in gas-to-liquid reactions: plasma promoted Fischer-Tropsch synthesis for hydrocarbons at low temperatures and ambient pressure. Green Process Synth 2(5): 479-490.

20. Taghvaei H, Heravi M, Rahimpour MR (2017) Synthesis of supported nanocatalysts via novel non-thermalplasma methods and its application in catalytic processes. Plasma Process Polym 14(6): 1-20.

21.Davis BH (2007) Fischer-Tropsch synthesis: comparison of performances of iron and cobalt catalysts. Ind Eng Chem Res 46(26): 8938-8945.
22. Aluha J, Bere K, Abatzoglou N, Gitzhofer F (2016) Synthesis of nanocatalysts by induction Suspension Plasma Technology (SPS) for FischerTropsch reaction. Plasma Chem Plasma Process 36(5): 1325-1348.

23. Voss M, Borgmann D, Wedler G (2002) Characterization of alumina, silica, and titania supported cobalt catalysts. J Catal 212(1): 10-21.

24. Riedel T, Schaub G (2003) Low-temperature Fischer-Tropsch synthesis on cobalt catalysts - effects of $\mathrm{CO}_{2}$. Top Catal 26(1-4): 145-156.

25. Aluha J, Boahene P, Dalai A, Hu Y, Bere K, et al. (2015) Synthesis and characterisation of nanometric $\mathrm{Co} / \mathrm{C}$ and $\mathrm{Fe} / \mathrm{C}$ catalysts for FischerTropsch synthesis: A comparative study using a fixed-bed reactor. Ind Eng Chem Res 54(43): 10661-10674.

26. Rutkovskii AE, Vishnyakov LR, Chekhovskii AA, Kirkun NI (2000) Use of plasma technology in creating catalysts on carriers. Powder Metall Met $\mathrm{C}^{+}$39(3-4): 207-209.

27. Liu CJ, Vissokov GP, Jang BWL (2002) Catalyst preparation using plasma technologies. Catal Today 72(3-4): 173-184.

28. Aluha-Lulizi J (2017) Low-temperature Fischer-Tropsch synthesis for production of synthetic fuels using nanometric carbon-supported iron and cobalt catalysts, PhD Thesis. Université de Sherbrooke, Sherbrooke (QC), Canada, pp. 281.

29. Blanchard J, Abatzoglou N, Eslahpazir-Esfandabadi R, Gitzhofer F (2010) Fischer-Tropsch synthesis in a slurry reactor using a nano-iron carbide catalyst produced by a plasma spray technique. Ind Eng Chem Res 49(15): 6948-6955.

30.Aluha J, Braidy N, Dalai A, Abatzoglou N (2016) Low-temperature Fischer-Tropsch synthesis using plasma- synthesised nanometric $\mathrm{Co} / \mathrm{C}$ and Fe/C catalysts. Can J Chem Eng 94(8): 1504-1515.

31. Aluha J, Hu Y, Abatzoglou N (2017) Effect of CO concentration on the $\alpha$-value of plasma-synthesized Co/C catalyst in Fischer-Tropsch synthesis. Catalysts 7(2): 1-69.

32. Aluha J, Abatzoglou N (2016) Synthetic fuels from 3- $\varphi$ Fischer-Tropsch synthesis using syngas feed and novel nanometric catalysts synthesised by plasma. Biomass Bioenerg 95(1): 330-339.

33. Aluha J, Abatzoglou N (2017) Promotional effect of Mo and Ni in plasmasynthesized $\mathrm{Co}-\mathrm{Fe} / \mathrm{C}$ bimetallic nano-catalysts for Fischer-Tropsch synthesis. J Ind Eng Chem 50: 199-212.

34. Boulos M, Pfender E (1996) Materials processing with thermal plasmas. MRS Bull 21(8): 65-68.

35. Moodley DJ, Loosdrecht VDJ, Saib AM, and Niemantsverdriet HJW (2010) The formation and influence of carbon on cobalt-based FischerTropsch synthesis catalysts: An integrated review. In: Davis BH, Occelli ML (eds.) Advances in Fisher Tropsch synthesis, catalysts and catalysis. CRC Press, USA, pp. 49-81.

36. Duvenhage DJ, Coville NJ (1997) Fe: Co/TiO bimetallic catalysts for the Fischer-Tropsch reaction I. Characterization and reactor studies. Appl Catal A 153: 43-67.

37. Calderone VR, Shiju NR, Ferré DC, Rothenberg G (2011) Bimetallic catalysts for the Fischer-Tropsch reaction. Green Chem 13(8):19501959.

38. Tavasoli A, Trépanier M, Abbaslou RMM, Dalai AK, Abatzoglou N, et al. (2009) Fischer-Tropsch synthesis on mono- and bimetallic Co and Fe catalysts supported on carbon nanotubes. Fuel Process Technol 90(12):1486-1494.

39. Ishihara T, Horiuchi N, Inoue T, Eguchi K, Takita Y, et al. (1992) Effect of alloying on $\mathrm{CO}$ hydrogenation activity over $\mathrm{SiO}_{2}$-supported $\mathrm{Co}$-Ni alloy catalysts. J Catal 136(1): 232-241.

40.Li S, O’Brien RJ, Meitzner GD, Hamdeh H, Davis BH, et al. (2001) Structural analysis of un promoted Fe-based Fischer-Tropsch catalysts using X-ray absorption spectroscopy. Appl Catal A 219(1-2): 215-222. 
41. Huyser J, Vuuren VMJ, Kupi G (2010) Advances in Fischer-Tropsch Synthesis, Catalysts, and Catalysis. In: Davis BH, Occelli ML (eds) The value of a two alpha model in the elucidation of a full product spetrum for Fe-LTFT, pp. 185-198.

42. Herranz T, Rojas S, Pérez-Alonso FJ, Ojeda M, Terreros P, et al. (2006) Genesis of iron carbides and their role in the synthesis of hydrocarbons from synthesis gas. J Catal 243(1):199-211.

43. Bezemer GL, Bitter JH, Kuipers HPCE, Oosterbeek H, Holewijn JE, et al. (2006) Cobalt particle size effects in the Fischer-Tropsch reaction studied with carbon nanofiber supported catalysts. J Am Chem Soc 128(12): 3956-3964.

44. Wang C, Xu L, Wang Q (2003) Review of directly producing light olefins via CO hydrogenation. J Nat Gas Chem 12(1): 10-16.

45. Laan VDGP, Beenackers AACM (1999) Hydrocarbon selectivity model for the gas-solid Fischer-Tropsch synthesis on precipitated iron catalysts. Ind Eng Chem Res 38(4): 1277-1290.

46. Dry ME (1982) Catalytic aspects of industrial Fischer-Tropsch synthesis. J Mol Catal 17(2-3):133-144.

47. Khassin AA, Yurieva TM, Parmon VN (1998) Fischer-Tropsch synthesis over cobalt-containing unsupported catalysts in slurry reactor. Effect of the metallic Co particle size on the catalyst selectivity. React Kinet Catal Lett 64(1): 55-62.

48. Liu JX, Wang P, Xu W, Hensen EJM (2017) Particle size and crystal phase effects in Fischer-Tropsch catalysts. Engineering 3(4): 467-476.

49. Cano LA, Cagnoli MV, Fellenz NA, Bengoa JF, Gallegos NG, et al. (2010) Fischer-Tropsch synthesis. Influence of the crystal size of iron active species on the activity and selectivity. Appl Catal A 379(1-2): 105-110.

50. Breejen DJP, Radstake PB, Bezemer GL, Bitter JH, Frøseth V, et al. (2009) on the origin of the cobalt particle size effects in Fischer-Tropsch catalysis. J Am Chem Soc 131(20): 7197-7203.

51. Ernst B, Libs S, Chaumette P, Kiennemann A (1999) Preparation and characterization of Fischer-Tropsch active $\mathrm{Co} / \mathrm{SiO}_{2}$ catalysts. Appl Catal A 186(1-2): 145-168.

52. Aluha J, Abatzoglou N (2017) Gold-promoted plasma-synthesized NiCo-Fe/C catalyst for Fischer-Tropsch synthesis. Gold Bull 50(2):147162.

53. Aluha J, Abatzoglou N, Gitzhofer F (2017) Plasma-synthesized carbonsupported nano-catalysts for Fischer-Tropsch synthesis. Conference Paper. The $23^{\text {rd }}$ International Symposium on Plasma Chemistry (ISPC 23), Montreal, (QC), Canada.

\section{Your next submission with Juniper Publishers will reach you the below assets}

- Quality Editorial service

- Swift Peer Review

- Reprints availability

- E-prints Service

- Manuscript Podcast for convenient understanding

- Global attainment for your research

- Manuscript accessibility in different formats ( Pdf, E-pub, Full Text, Audio)

- Unceasing customer service

Track the below URL for one-step submission https://juniperpublishers.com/online-submission.php 